\title{
Reduction characteristics of copper oxide in cerium and zirconium oxide systems
}

\author{
Lj. Kundakovic, M. Flytzani-Stephanopoulos* \\ Department of Chemical Engineering, Tufts University, 4 Colby Street, Medford, MA 02155, USA
}

Received 21 July 1997; received in revised form 5 January 1998; accepted 17 January 1998

\begin{abstract}
The reduction of $\mathrm{CuO}$ dispersed on fluorite-type oxide catalysts, namely $\mathrm{La}$-doped $\mathrm{CeO}_{2}$ and $\mathrm{Y}$-doped $\mathrm{ZrO}_{2}$ was studied in this work. On both supports distinct copper species were identified as a function of copper content by temperatureprogrammed reduction (TPR) by $\mathrm{H}_{2}$ and $\mathrm{CH}_{4}$, X-ray photoelectron spectroscopy (XPS), X-ray powder diffraction (XRD) and scanning transmission electron microscopy/energy dispersive X-ray (STEM/EDX) analyses. At low copper loading $(<15$ at $\%)$, the copper phase is present as small clusters, which are reduced at lower temperature than bulk $\mathrm{CuO}$. At higher $\mathrm{Cu}$ loading $(>15$ at\%), in addition to clusters, larger $\mathrm{CuO}$ particles are present which are reduced at higher temperature close to the reduction temperature of bulk $\mathrm{CuO}$. At copper loading lower than ca. 5 at\%, copper is present as highly dispersed clusters or isolated $\mathrm{Cu}$ ions, which interact strongly with the fluorite-type oxide, thus requiring higher reduction temperature. However, the latter is still below the bulk $\mathrm{CuO}$ reduction temperature. Copper is more stabilized when dispersed in $\mathrm{Ce}(\mathrm{La}) \mathrm{O}_{2}$ than in $\mathrm{Zr}(\mathrm{Y}) \mathrm{O}_{2}$ matrix, so that reduction of copper oxide species requires lower temperatures on the $\mathrm{Zr}(\mathrm{Y}) \mathrm{O}_{2}$-based catalysts. The reducibility of the doped ceria is enhanced by the presence of copper in both $\mathrm{H}_{2}$ - and $\mathrm{CH}_{4}$-TPR. On the other hand no such interaction is present in $\mathrm{CuZr}(\mathrm{Y}) \mathrm{O}_{2}$ system. The activity of various copper species for methane oxidation is discussed. (C) 1998 Elsevier Science B.V. All rights reserved.
\end{abstract}

Keywords: Cerium oxide; Reducibility; Copper oxide; Zirconium oxide; Temperature-programmed-reduction; Catalytic methane oxidation

\section{Introduction}

$\mathrm{CeO}_{2}$ is used as a promoter in the three-way catalyst (TWC) for automotive emission control and is a component of several oxidation catalysts [1]. Ceria is well known for its high oxygen storage capacity [24], stabilization of the surface area of the alumina

\footnotetext{
*Corresponding author. Tel.: 001 6176273048; fax: 001 6176273991 .
}

support, and interaction with the noble metals $\mathrm{Rh}, \mathrm{Pt}$ and Pd [1,5-10]. The strong interaction between platinum metals and ceria enhances the metal dispersion and the oxygen storage capacity of ceria. Addition of noble metals (Pt, Pd) increases the reactivity of low-temperature oxygen species formed on ceria $[11,12]$. As a result, the reducibility of ceria at low temperatures is enhanced [13,14].

Recent reports have shown that the activity of ceria in complete oxidation reactions can be largely enhanced not only by the platinum metals but also 
by transition metals in general [15-17]. Large synergistic effects over copper-containing ceria were reported for $\mathrm{CO}$ oxidation $[18,19], \mathrm{SO}_{2}$ reduction by $\mathrm{CO}$ to elemental sulfur [20,21], and the watergas-shift reaction [22]. In a recent paper, Liu and Flytzani-Stephanopoulos [22] used a physical mixture of nano-CuO particles and ceria to show that association of copper and ceria results in enhanced reducibility of both oxides.

Furthermore, a copper-containing ceria was reported as a very active catalyst for the total oxidation of methane $[18,19]$. This catalyst showed higher activity than $\mathrm{Pt} / \mathrm{Al}_{2} \mathrm{O}_{3}$ or perovskites [17]. Thus, it may offer a low-cost alternative to $\mathrm{PdO}_{x}$-based catalysts, which are presently the most active catalysts for the complete oxidation of methane at low temperatures. In the literature, we also find mention of the high methane oxidation activity for copper oxide supported on zirconia [17-19,23].

It is interesting to compare the activity of these two types of copper-containing systems. While both ceria and zirconia can disperse copper oxide [17], the former is a reducible oxide that can itself participate in complete oxidation reactions.

The reducibility of copper species on ceria and zirconia can be used to characterize these systems. Several studies of the ceria reduction characteristics have appeared in the literature, especially of platinum metal-modified ceria, and more recently of solid solutions of ceria with zirconia. A good review is given by Trovarelli [1]. Temperature-programmed reduction (TPR) has been used to characterize the surface and bulk oxygen reducibility of these modified cerium oxide systems $[3,4,13,24,25]$.

TPR has also been used to characterize supported copper oxide catalysts. Typically hydrogen was used as the reductant $\left(\mathrm{H}_{2}\right.$-TPR). In their study of deactivation of $\mathrm{Cu}-\mathrm{ZSM}-5$ zeolite catalysts for the selective catalytic reduction of $\mathrm{NO}$, Yan et al. [26] used $\mathrm{H}_{2}$-TPR to compare the reduction of copper on various supports. Bulk $\mathrm{CuO}$ has been reported to reduce at 200 $300^{\circ} \mathrm{C}$ [27]. Support effects on the dispersion and reducibility of copper oxide have been documented in the literature $[28,29]$.

In the case of $\mathrm{H}_{2}$-TPR of silica-supported copper, Delk and Vavere [30] reported two reduction peaks $\left(229^{\circ} \mathrm{C}\right.$ and $\left.268^{\circ} \mathrm{C}\right)$ for 1 and $4 \mathrm{wt} \%$ copper, respectively. Yan et al. [26] observed a $\mathrm{H}_{2}$ consumption peak at $200^{\circ} \mathrm{C}$ for $2 \mathrm{wt} \% \mathrm{Cu}$ on silica. The same authors [26], for $1 \mathrm{wt} \% \mathrm{Cu}$ on alumina observed reduction of small $\mathrm{CuO}$ clusters at $130^{\circ} \mathrm{C}$, accompanied by a broad reduction peak in the range $100-500^{\circ} \mathrm{C}$, attributed to copper aluminate. The $\mathrm{Cu}$-exchanged ZSM-5 reduction profile had three reduction peaks located at $15^{\circ} \mathrm{C}$, $165^{\circ} \mathrm{C}$ and $275^{\circ} \mathrm{C}$ [26]. The low-temperature peak $\left(15^{\circ} \mathrm{C}\right)$ was assigned to the reduction of bridged oxocations to $\mathrm{Cu}^{+1}$, the $165^{\circ} \mathrm{C}$ reduction peak was assigned to the reduction of isolated $\mathrm{Cu}^{+2}$ ions to $\mathrm{Cu}^{+1}$, and reduction of $\mathrm{CuO}$ clusters, while the high temperature peak $\left(275^{\circ} \mathrm{C}\right)$ was assigned to the reduction of $\mathrm{Cu}^{+1}$ to metallic copper [26,31,32]. Amenomiya et al. [33] observed two reduction peaks in $\mathrm{H}_{2}$ TPR of $\mathrm{CuO} / \mathrm{ZrO}_{2}$ : at low $\mathrm{CuO}$ loading $(10 \mathrm{wt} \% \mathrm{CuO})$ reduction was observed at about $200^{\circ} \mathrm{C}$, while at higher $\mathrm{CuO}$ loading $(40 \mathrm{wt} \%)$ a second reduction peak was observed at around $300^{\circ} \mathrm{C}$. Kung et al. [34] reported a similar reduction profile of the $\mathrm{CuO} /$ $\mathrm{ZrO}_{2}$ system, but at lower reduction temperatures $\left(134^{\circ} \mathrm{C}\right.$ for $7.4 \mathrm{wt} \%$ copper and both $134^{\circ} \mathrm{C}$ and $180^{\circ} \mathrm{C}$ for $33 \mathrm{wt} \%$ copper). Dow and Huang [28] reported reduction of 1 and $5 \mathrm{wt} \% \mathrm{Cu}$ on yttriastabilized zirconia at $250^{\circ} \mathrm{C}$ and $274^{\circ} \mathrm{C}$, respectively. Two reduction peaks were reported by Liu and Flytzani-Stephanopoulos [22] for physical mixtures of nano-CuO particles and ceria: reduction of copper oxide clusters, strongly interacting with ceria, was observed in the range $125-175^{\circ} \mathrm{C}$ with a peak at $167^{\circ} \mathrm{C}$, while larger $\mathrm{CuO}$ nano-particles, non-associated with ceria were reduced at $\sim 200^{\circ} \mathrm{C}$. Wrobel et al. [35] observed copper reduction in the range 120$150^{\circ} \mathrm{C}$ in $\mathrm{Cu}-\mathrm{CeO}_{2}$ mixed oxides $(20-67$ at $\% \mathrm{Cu})$.

Differences in the reduction of copper oxide may be partially attributed to the range of operating conditions used. The type of the support is known to affect particle morphology, adsorption and catalytic properties. Farrauto et al. [36] have shown that the PdO reduction/oxidation hysteresis strongly depends on the nature of the support. In addition, several authors have reported an influence of particle size on the catalytic activity when noble metals are used for methane oxidation. Otto [37] found a maximum in the turnover frequency and a decrease in the apparent activation energy for methane oxidation with increasing Pt content on alumina from 0.03 to $30 \mathrm{wt} \%$. These differences were attributed to the existence of two distinct Pt entities, namely dispersed and particulate Pt. Recently, 
Fujimoto et al. [38] showed that the turnover rate of methane oxidation increases as the crystallite size increases up to $10 \mathrm{~nm}$, while the activation energy stays constant, when Pd is supported on alumina or zirconia.

In this study we examined the interaction of $\mathrm{CuO}$ with two fluorite-type oxides, namely La-doped $\mathrm{CeO}_{2}$ and Y-doped $\mathrm{ZrO}_{2}$. Different copper species are formed on these supports depending on the copper content. We used $\mathrm{H}_{2}$-TPR to study the reducibility of $\mathrm{CuO}$ species formed as a function of the $\mathrm{CuO}$ particle size and the type of the support. Catalyst structure was studied by X-ray powder diffraction (XRD), X-ray photoelectron spectroscopy (XPS) and scanning transmission electron microscopy/energy dispersive X-ray analysis (STEM/EDX). $\mathrm{CH}_{4}$-TPR was used to study the reactivity of various copper species with methane. Finally, the activity of different copper species in the complete oxidation of methane was examined and discussed in terms of the light-off behavior and kinetic performance.

\section{Experimental}

The Cu-modified fluorite-type oxides were prepared in bulk form by coprecipitating nitrate salts by urea at about $100^{\circ} \mathrm{C}$, according to a technique described by Amenomiya et al. [33] and Kung et al. [34]. After coprecipitation, the resulting gels of $\mathrm{Ce}$ and $\mathrm{Zr}$ were vigorously boiled for $8 \mathrm{~h}$ at $100^{\circ} \mathrm{C}$. After aging, the precipitate was filtered, washed twice in boiling deionized water, and dried in a preheated vacuum oven $\left(80-100^{\circ} \mathrm{C}\right)$ for $8-10 \mathrm{~h}$. Dried samples were crushed and calcined in air for $6-8 \mathrm{~h}$ at $650^{\circ} \mathrm{C}$ (heating rate was $2^{\circ} \mathrm{C} / \mathrm{min}$ ). Selected catalysts were immersed in $70 \%$ nitric acid for $8 \mathrm{~h}$ to dissolve $\mathrm{CuO}$ particles, washed with deionized water, dried at $100^{\circ} \mathrm{C}$ $(8-10 \mathrm{~h})$ and calcined at $650^{\circ} \mathrm{C}$ for $4 \mathrm{~h}$.

The catalyst composition throughout the paper is expressed as at $\%$ (metal/total metals $\times 100 \%$ ). All catalysts used in this study were doped with 4.5 at $\% \mathrm{La}$ (for $\mathrm{CeO}_{2}$-based catalysts) or 4.5 at\% Y (for $\mathrm{ZrO}_{2}$-based catalysts).

For bulk composition analysis the $\mathrm{CeO}_{2}$-based powder was dissolved in nitric acid containing a small amount of $\mathrm{H}_{2} \mathrm{O}_{2}$ diluted with deionized water and the resulting solution was analyzed by Inductively
Coupled Plasma (ICP) Atomic Emission Spectrometry (Perkin Elmer Plasma 40 ). $\mathrm{ZrO}_{2}$-based catalysts could not be dissolved and analyzed by this method.

XRD analysis of catalyst samples was used for crystal phase identification. XRD was performed on a Rigaku 300 X-ray Diffractometer with Rotating Anode Generators and monochromatic detector using $\mathrm{Cu} \mathrm{K}_{\alpha}$ radiation.

The catalyst microstructure analysis was performed on a Vacuum Generator HB603 STEM equipped with a X-ray microprobe of $0.14 \mathrm{~nm}$ optimum resolution for EDX. For STEM analysis, the catalyst powder was dispersed on a nickel grid coated with a carbon film and elemental maps were obtained on a $128 \times 128$ data matrix.

The catalyst surface composition was studied by XPS using a Perkin Elmer-5100 system. A Mg electron source was used with a power setting at $300 \mathrm{~W}$. Samples were introduced in the vacuum chamber without any pretreatment. The binding energy was adjusted to the $\mathrm{C} 1 s$ peak at $284.6 \mathrm{eV}$, which existed in all measurements. It is known that supported copper oxide can be reduced in the vacuum chamber. As in previous study of $\mathrm{CuCe}(\mathrm{La}) \mathrm{O}_{2}$ by Liu and FlytzaniStephanopoulos [19], each sample was analyzed after $1 \mathrm{~h}$ in the vacuum, to obtain stable spectra. Data were collected in the Multiplex mode with about $1 \mathrm{~h}$ acquisition time.

TPR studies with $\mathrm{H}_{2}$ and $\mathrm{CH}_{4}$ as reductants were performed in a Cahn 121 thermogravimetric analyzer (TGA). Typically about $5 \mathrm{mg}$ of catalyst was used in the TGA for TPR analysis. Prior to reduction the catalyst was heated to $200^{\circ} \mathrm{C}\left(10^{\circ} \mathrm{C} / \mathrm{min}\right)$ and left at that temperature for $30 \mathrm{~min}$ in $500 \mathrm{~cm}^{3} / \mathrm{min}$ (STP) He. The reduction gas was typically $5 \% \mathrm{H}_{2} / \mathrm{He}$ (or $5 \%$ $\mathrm{CH}_{4} / \mathrm{He}$ ) mixture flowing at $500 \mathrm{~cm}^{3} / \mathrm{min}$ (STP). The heating rate was typically $5^{\circ} \mathrm{C} / \mathrm{min}$.

$\mathrm{CH}_{4}$-TPR by methane was also performed in a laboratory-scale packed-bed reactor. Typically $200 \mathrm{mg}$ catalyst was used for testing. Pretreatment included heating the catalyst in a flow of $10 \% \mathrm{O}_{2} / \mathrm{He}$ mixture $\left(60 \mathrm{~cm}^{3} / \mathrm{min}(\mathrm{STP})\right)$ to $650^{\circ} \mathrm{C}$ at a heating rate $10^{\circ} \mathrm{C} / \mathrm{min}$, followed by cooling to room temperature in $\mathrm{O}_{2} / \mathrm{He}$ mixture, and flushing with $\mathrm{He}$ at room temperature. A $5 \% \mathrm{CH}_{4} / \mathrm{He}$ gas mixture at a flow rate of $60 \mathrm{~cm}^{3} / \min$ (STP) was used for reduction. The outlet gas was analyzed by a quadrupole mass spectrometer (MKS-model RS-1). 
All catalysts were tested in a laboratory-scale packed-bed flow reactor, which consisted of $1 \mathrm{~cm}$ ID $\times 50 \mathrm{~cm}$ long quartz tube with a porous quartz frit placed at the middle. An electric furnace was used to heat the reactor. Temperature was monitored by a Ktype thermocouple placed at the top of the catalyst bed, and controlled by a Wizard temperature controller. The flow of reacting gases was measured by mass flow meters. The typical feed gas was $1 \% \mathrm{CH}_{4}, 8 \% \mathrm{O}_{2}$ and balance He. All gases were certified calibration gas mixtures. The catalyst loading was $150 \mathrm{mg}$ unless otherwise noted. The catalysts were tested as prepared without any pretreatment (particle size $<153 \mu \mathrm{m}$ ), and conversion measurements were conducted in ascending temperature mode (in $50^{\circ} \mathrm{C}$ steps), so that the lightoff behavior could be recorded. These were followed by descending temperature tests (fall-off) to check for possible catalyst deactivation or hysteresis phenomena. A fixed contact time of $0.09 \mathrm{~g} \mathrm{~s} / \mathrm{cm}^{3}$ (STP) was used in these experiments unless otherwise noted. The product gas stream was analyzed by an HP 5880A gas chromatograph equipped with a 1/4 in. Carbosphere column (for $\mathrm{CO}, \mathrm{CO}_{2}$ and $\mathrm{CH}_{4}$ separation) and a thermal conductivity detector (TCD).

For kinetic measurements, the reactor was operated in the differential mode with the conversion not exceeding $10 \%$. The total flow rate was $200 \mathrm{~cm}^{3} /$ $\min$ (STP). The catalyst was diluted by silicon carbide particles to achieve the short contact times $(0.024 \mathrm{~g} \mathrm{~s} /$ $\mathrm{cm}^{3}$ ) needed for operation in the kinetically controlled regime. The catalyst particle size used in the kinetic experiments was $<50 \mu \mathrm{m}$.

\section{Results and discussion}

\subsection{Complete oxidation of methane activity tests}

The activity of $\mathrm{Cu}$-modified $\mathrm{Ce}(\mathrm{La}) \mathrm{O}_{2}$ and $\mathrm{Zr}(\mathrm{Y}) \mathrm{O}_{2}$ catalysts for the complete oxidation of methane was examined in terms of light-off behavior as shown in Fig. 1(a) and (b). At a contact time $0.09 \mathrm{~g} \mathrm{~s} / \mathrm{cm}^{3}$ (STP), equivalent to a gas hourly space velocity, $\mathrm{GHSV}=72000 \mathrm{~h}^{-1}$, both $\mathrm{CuCe}(\mathrm{La}) \mathrm{O}_{2}$ and $\mathrm{Cu}-$ $\mathrm{Zr}(\mathrm{Y}) \mathrm{O}_{2}$ are active for complete methane oxidation to $\mathrm{CO}_{2}$ and $\mathrm{H}_{2} \mathrm{O}$ in the temperature range $300-550^{\circ} \mathrm{C}$. Only $\mathrm{CO}_{2}$ was detected as the oxidation product under both oxygen-rich and oxygen-lean (data not shown) conditions. $\mathrm{CeO}_{2}$ itself is an active catalyst for the complete oxidation of methane $[18,19,39]$ at temperatures higher than $400^{\circ} \mathrm{C}$ (Fig. 1(a)). Addition of $\mathrm{Cu}$ shifts the light-off curve to lower temperatures on both types of supports, indicating the formation of new active sites. A shift of more than $100^{\circ} \mathrm{C}$ is observed for both the $10 \%$ and $90 \%$ conversion of methane in Fig. 1(a) for copper loading up to 20 at $\%$. At 40 at $\% \mathrm{Cu}$, the light-off performance is between the low copper content $\mathrm{CuCe}(\mathrm{La}) \mathrm{O}_{2}$ and the $\mathrm{Ce}(\mathrm{La}) \mathrm{O}_{2}$ catalysts. Similar trends are observed in Fig. 1(b) for the $\mathrm{CuZr}(\mathrm{Y}) \mathrm{O}_{2}$ and $\mathrm{Zr}(\mathrm{Y}) \mathrm{O}_{2}$ systems. In addition to $\mathrm{CO}_{2}, \mathrm{CO}$ was detected as the oxidation product over Y-doped zirconia (in the absence of copper) as noted in Fig. 1(b). Undoped zirconia (monoclinic) is inactive for the complete oxidation of methane (Fig. 1(b)) in the temperature range studied. Different observations were made by Choudhary et al. [23] who reported $\sim 30 \%$ conversion of methane at $600^{\circ} \mathrm{C}\left(1 \% \mathrm{CH}_{4}\right.$ in air, GHSV $=51000 \mathrm{~h}^{-1}$ ) on monoclinic zirconia (no $\mathrm{CO}$ was detected). However, Zamar et al. [39] reported only $5 \%$ methane conversion over zirconia at the same temperature $\left(1 \% \mathrm{CH}_{4}, 4 \% \mathrm{O}_{2}, \mathrm{GHSV}=34000 \mathrm{~h}^{-1}\right)$ with significant amounts of $\mathrm{CO}$ produced (crystal structure was not reported).

\subsection{Catalyst characterization}

The conventional $\mathrm{N}_{2} \mathrm{O}$ adsorption/decomposition method [40] could not be used to estimate the copper particle size because of the significant participation of $\mathrm{CeO}_{2}$. However, STEM, having both high magnification and elemental analysis function, was found to be effective for the $\mathrm{CuCe}(\mathrm{La}) \mathrm{O}_{2}$ catalyst characterization [17].

Fig. 2 shows STEM/EDX elemental mapping of copper in $\mathrm{Zr}(\mathrm{Y}) \mathrm{O}_{2}$ catalysts. At low content $(<5$ at $\%)$, copper is well dispersed in the zirconia matrix (Fig. 2(a)). Atomic dispersion of $\mathrm{Y}$ was observed indicating the formation of oxide solid solution. This agrees with our XRD data (see below), where only the phase of cubic zirconia was observed. Addition of more copper (up to 15 at \%) results in the formation of clusters, and their aggregation to larger particles $(\sim 10 \mathrm{~nm})$, which are still dispersed in the zirconia matrix as shown in Fig. 2(b). Elemental mapping of $40 \% \mathrm{CuZr}(\mathrm{Y}) \mathrm{O}_{2}$ catalysts shows the presence of large $\mathrm{CuO}$ particles (Fig. 2(c)). Large $\mathrm{CuO}$ particles are 

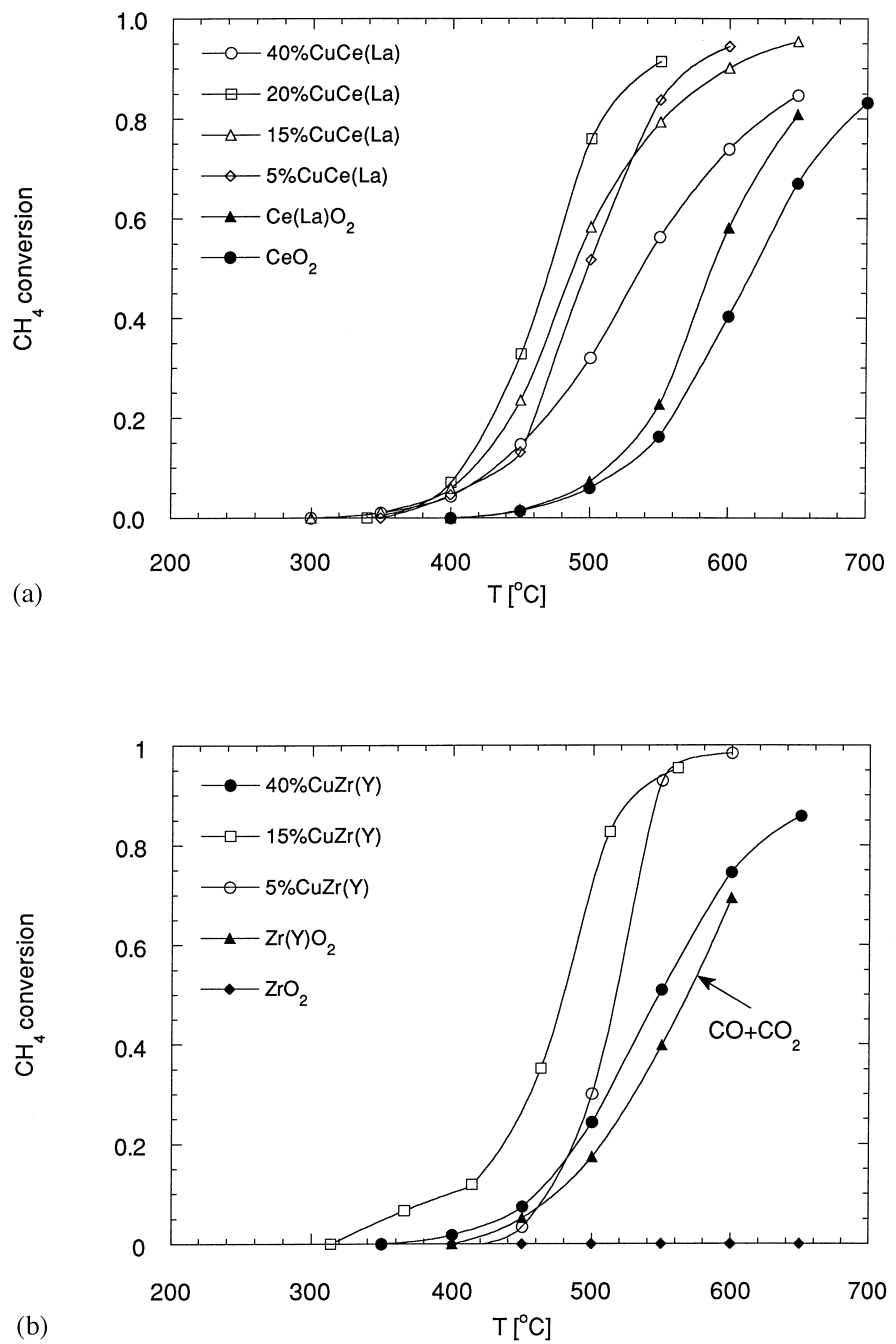

Fig. 1. (a) Activity of various $\mathrm{Cu}$-modified $\mathrm{Ce}(\mathrm{La}) \mathrm{O}_{2}$-based catalysts: $2 \% \mathrm{CH}_{4}, 16 \% \mathrm{O}_{2}$, balance $\mathrm{He}, 0.09 \mathrm{~g} \mathrm{~s} / \mathrm{cm}^{3}(\mathrm{STP}) ; \mathrm{CeO}_{2}: 70.2 \mathrm{~m}^{2} / \mathrm{g}$; $\mathrm{Ce}(\mathrm{La}) \mathrm{O}_{2}: 69.1 \mathrm{~m}^{2} / \mathrm{g} ; 5 \% \mathrm{CuCe}(\mathrm{La}) \mathrm{O}_{2}: 92.1 \mathrm{~m}^{2} / \mathrm{g} ; 15 \% \mathrm{CuCe}(\mathrm{La}) \mathrm{O}_{2}: 32.3 \mathrm{~m}^{2} / \mathrm{g} ; 20 \% \mathrm{CuCe}\left(\mathrm{La}_{2} \mathrm{O}_{2}: 49.2 \mathrm{~m}^{2} / \mathrm{g} ; 40 \% \mathrm{CuCe}(\mathrm{La}) \mathrm{O}_{2}: 36.5 \mathrm{~m}^{2} / \mathrm{g}\right.$. (b) Activity of various $\mathrm{Cu}$-modified $\mathrm{Zr}(\mathrm{Y}) \mathrm{O}_{2}$ catalysts: $2 \% \mathrm{CH}_{4}, 16 \% \mathrm{O}_{2}$, balance $\mathrm{He}, 0.09 \mathrm{~g} \mathrm{~s} / \mathrm{cm}^{3} ; \mathrm{ZrO}_{2}: 43.5 \mathrm{~m}^{2} / \mathrm{g} ; \mathrm{Zr}(\mathrm{Y}) \mathrm{O}_{2}: 101.2 \mathrm{~m} / \mathrm{g}$; $5 \% \mathrm{CuZr}(\mathrm{Y}) \mathrm{O}_{2}: 94.6 \mathrm{~m}^{2} / \mathrm{g} ; 15 \% \mathrm{CuZr}(\mathrm{Y}) \mathrm{O}_{2}: 44.1 \mathrm{~m}^{2} / \mathrm{g} ; 40 \% \mathrm{CuZr}(\mathrm{Y}) \mathrm{O}_{2}: 29.6 \mathrm{~m}^{2} / \mathrm{g}$.

covered by zirconia. However, the remaining copper is well dispersed in the zirconia matrix. Large $\mathrm{CuO}$ particles were removed with nitric acid treatment, as shown in Fig. 2(d). In addition, Fig. 2(d) shows that not all copper was dissolved in nitric acid, indicating that well dispersed copper clusters interact strongly with the zirconia support. This is similar to what has been reported by $\mathrm{Liu}$ [17] for the $\mathrm{CuCe}(\mathrm{La}) \mathrm{O}_{2}$ system. It is interesting to note that zirconia is present as small $(<15 \mathrm{~nm})$ crystallites after calcination at $650^{\circ} \mathrm{C}$.
In their study of $\mathrm{CuCe}(\mathrm{La}) \mathrm{O}_{2}$ catalysts, Liu and Flytzani-Stephanopoulos [19] showed that $\mathrm{Cu}$ in small amounts (few percent) associates strongly with the cerium oxide matrix. Clusters of copper (few nm) well dispersed in the cerium oxide matrix were clearly observed. At higher $\mathrm{Cu}$ loading, in addition to clusters, larger $\mathrm{CuO}$ particles $(>10 \mathrm{~nm})$ were formed. At high $\mathrm{Cu}$ contents $(50$ at\%), bulk $\mathrm{CuO}$ particles were covered with smaller cerium oxide particles. On the other hand, at a very low content of copper (1 at\%) atomic 
(a)
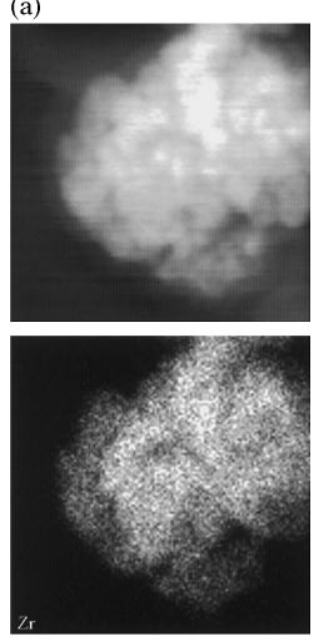

(c)
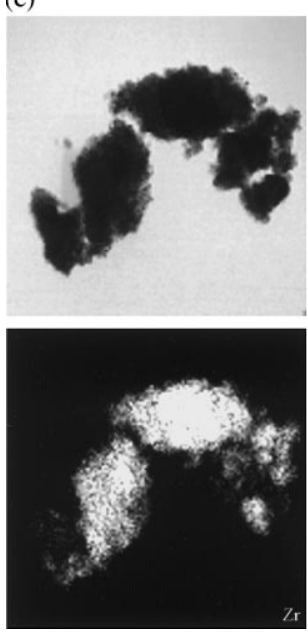
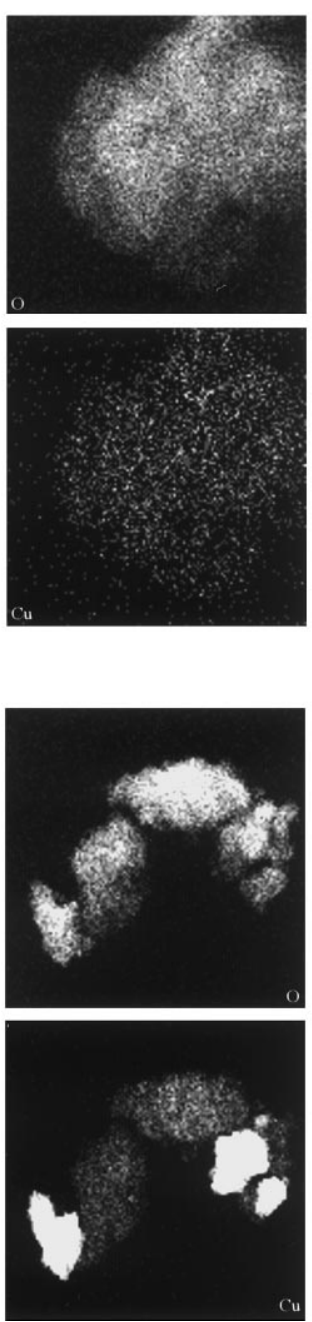

(b)
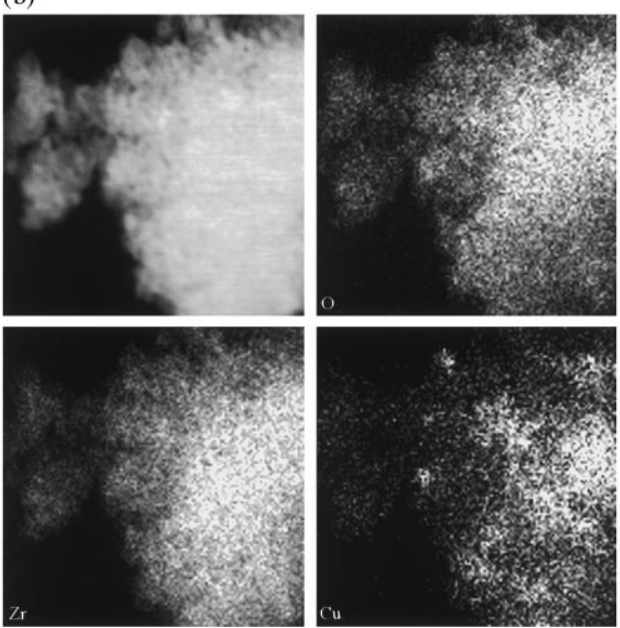

(d)
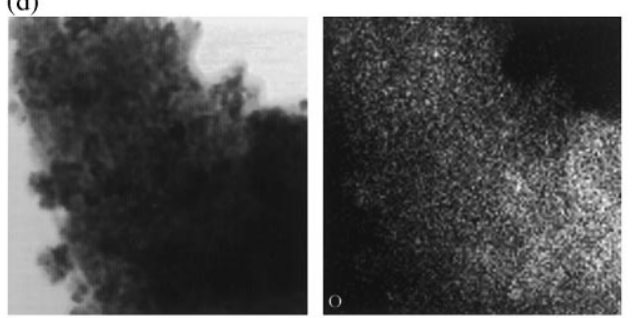

$100 \mathrm{~nm}$
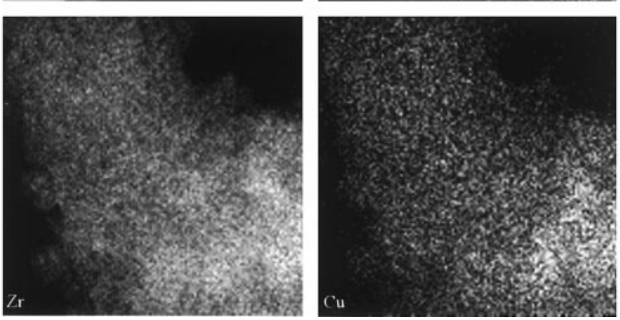

Fig. 2. STEM/EDX elemental mapping of Cu-modified $\mathrm{Zr}(\mathrm{Y}) \mathrm{O}_{2}$-based catalysts: (a) $5 \% \mathrm{CuZr}(\mathrm{Y}) \mathrm{O}_{2}$; (b) $15 \% \mathrm{CuZr}(\mathrm{Y}) \mathrm{O}_{2}$; (c) $40 \%$ $\mathrm{CuZr}(\mathrm{Y}) \mathrm{O}_{2}$; (d) $40 \% \mathrm{CuZr}(\mathrm{Y}) \mathrm{O}_{2}$ after nitric acid treatment.

dispersion of copper in the cerium oxide matrix was possible by calcining in $\mathrm{N}_{2}$ at low temperature $\left(500^{\circ} \mathrm{C}\right)$. High-temperature treatment, however, drove the copper from the bulk to the surface, and caused the formation of copper clusters [19].

XRD analysis of $\mathrm{Cu}$-modified $\mathrm{CeO}_{2}$ and $\mathrm{ZrO}_{2}$ catalysts did not identify the $\mathrm{CuO}$ phase for $\mathrm{Cu}$ contents lower than 15 at\%. In a previous study by Liu and Flytzani-Stephanopoulos [19], XRD analysis of $\mathrm{CuCe}(\mathrm{La}) \mathrm{O}_{2}$ catalysts with various copper contents identified $\mathrm{CuO}$ only at $\mathrm{Cu}$ levels higher than 15 at\%. Similar behavior was found here for the $\mathrm{CuZr}(\mathrm{Y}) \mathrm{O}_{2}$ catalysts as shown in Fig. 3. For $\mathrm{Cu}$ loading $<15$ at $\%$ only the zirconia phase was observed. At higher $\mathrm{Cu}$ loading, $\mathrm{CuO}$ reflections were observed indicating the formation of bulk $\mathrm{CuO}$. As in the case of ceria, the type of $\mathrm{CuO}$ formed at low and high loading is different. Treating the catalyst overnight in nitric acid resulted in the removal of bulk $\mathrm{CuO}$ particles while highly dispersed clusters could not be removed. Nanosized copper clusters identified by STEM/EDX are not detected by XRD. At low $\mathrm{Cu}$ loading $\mathrm{CuO}$ is either in the zirconia lattice as indicated by Choudhary et al. [23] or it is strongly bound and well dispersed on the 


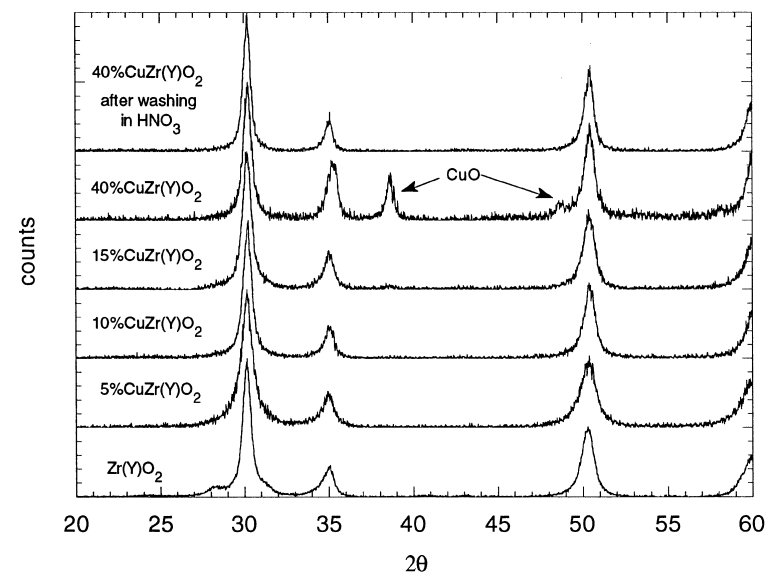

Fig. 3. XRD pattern of $\mathrm{CuZr}(\mathrm{Y}) \mathrm{O}_{2}$ catalysts with different $\mathrm{Cu}$ content.

surface of zirconia. In the absence of copper, the major phase is cubic zirconia with trace amounts of the monoclinic phase, which can be seen at low diffraction angles (Fig. 3). In Cu-containing catalysts, only the presence of cubic zirconia is observed. This is in agreement with the work of Choudhary et al. [23], who reported the stabilization of cubic zirconia by the addition of transition metals. This means that some of the copper (apparently a very small amount) is incorporated in the zirconia lattice.

Catalyst surface composition was studied by XPS. Fig. 4 shows $\mathrm{Cu} 2 p$ XPS of various $\mathrm{CuZr}(\mathrm{Y}) \mathrm{O}_{2}$ catalysts. Binding energy of $933.0-933.8 \mathrm{eV}$ for the

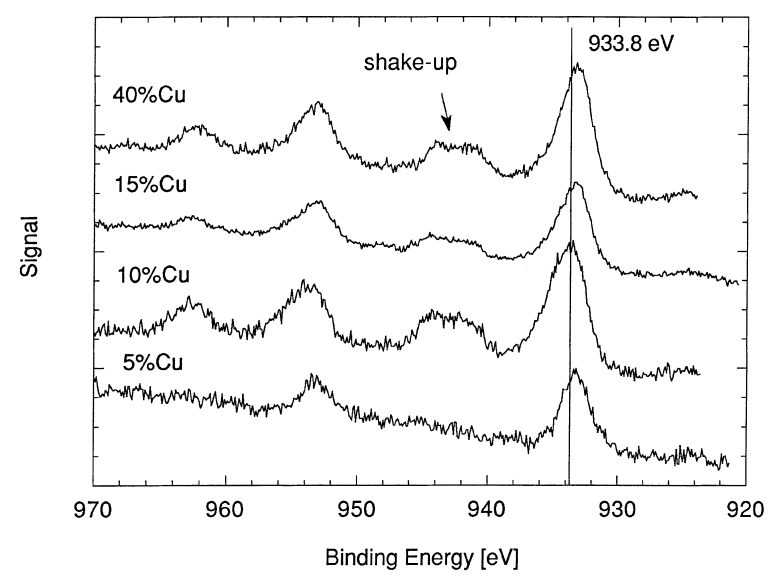

Fig. 4. $\mathrm{Cu} 2 p$ XPS of $\mathrm{CuZr}(\mathrm{Y}) \mathrm{O}_{2}$ catalysts.
Table 1

$\mathrm{Cu} 2 p_{3 / 2}$ binding energies and surface composition determined by XPS of $\mathrm{CuZr}(\mathrm{Y})$ catalysts

\begin{tabular}{lll}
\hline Catalyst & $\begin{array}{l}\mathrm{Cu} 2 p_{3 / 2} \text { binding } \\
\text { energy }(\mathrm{eV})\end{array}$ & $\begin{array}{l}\text { Surface composition } \\
(\text { at\% Cu })\end{array}$ \\
\hline $5 \% \mathrm{CuZr}(\mathrm{Y})$ & 933.3 & 10.2 \\
$10 \% \mathrm{CuZr}(\mathrm{Y})$ & 933.7 & 25.9 \\
$15 \% \mathrm{CuZr}(\mathrm{Y})$ & 933.3 & 27.4 \\
$40 \% \mathrm{CuZr}(\mathrm{Y})$ & 933.2 & 36.99 \\
\hline
\end{tabular}

$\mathrm{Cu} 2 p_{3 / 2}$ peak and shake-up peaks are characteristic for $\mathrm{CuO}$, while lower binding energy (932.2$933.1 \mathrm{eV}$ ) and absence of shake-up peaks is characteristic for $\mathrm{Cu}_{2} \mathrm{O}$ [41]. The binding energy of $\mathrm{Cu} 2 p_{3 / 2}$ peaks are listed in Table 1 for different copper contents. Our results indicate that copper is present as $\mathrm{CuO}$ at copper contents higher than 10 at\% as indicated by shake-up peaks in Fig. 4. The absence of shake-up peaks in $5 \% \mathrm{CuZr}(\mathrm{Y}) \mathrm{O}_{2}$ catalysts suggests the presence of reduced copper species. It seems that small clusters of copper present at low copper contents, which could not be dissolved by nitric acid and which are identified by STEM (Fig. 2) do not have the identity of $\mathrm{CuO}$. However, the measured binding energy is slightly higher than that for $\mathrm{Cu}_{2} \mathrm{O}$. It is known that nanosize particles have properties different than bulk oxides, and this mixed oxidation state could be the result of the defective structure of the small clusters. It is also possible that oxygen vacancies in $\mathrm{Zr}(\mathrm{Y}) \mathrm{O}_{2}$ stabilize the $\mathrm{Cu}^{+}$species as was postulated by Dow and Huang [28] and Dow et al. [29]. Surface composition analysis shows that copper is mostly at the catalyst surface. Up to 15 at $\%$, the surface copper content is higher than the bulk (Table 1). Only at 40 at $\% \mathrm{Cu}$, copper surface content is lower than the bulk. This is in agreement with STEM/EDX data which showed that excess copper at this high loading forms bulk $\mathrm{CuO}$ particles, which are covered by smaller zirconia particles, so that they are not detected by XPS. Similar behavior was previously reported for $\mathrm{CuCe}(\mathrm{La}) \mathrm{O}_{2}[22,23]$.

\subsection{TPR experiments}

\subsection{1. $H_{2}-T P R$}

In the TPR experiments reported here, TPR profiles were obtained by following the weight change of the 
sample in the TGA. The experimental conditions used are different from those usually employed in TPR studies. A typical experimental setup for TPR includes a microreactor that can be heated by a furnace [42]. The uptake of hydrogen is then recorded as a function of temperature using a TCD. In this study, we performed TPR in the TGA using a small amount of catalyst $(5 \mathrm{mg})$. Since reduction was followed by recording the weight change, the TPR profiles reflect changes occurring on the catalyst (water desorption) rather than $\mathrm{H}_{2}$ uptake. In their study of ceria reduction by hydrogen, Zotin et al. [43] have shown that the extent of ceria reduction at low temperatures can be overestimated if only $\mathrm{H}_{2}$ consumption is measured due to hydrogen adsorption on partially reduced ceria. In the conventional TPR method where hydrogen consumption is recorded using a TCD, typical flow conditions (low flow rate) do not provide effective water removal and hydrogen concentration changes throughout the catalyst bed. The advantage of using TGA experiments is that high flow rates are used, so that external mass transfer resistance is eliminated and $\mathrm{H}_{2}$ consumption is much lower than the total $\mathrm{H}_{2}$ supply, so that the hydrogen concentration is constant throughout the reduction process.

The reduction profile is markedly affected by the operating conditions, such as the initial amount of reducible species, total flow rate, hydrogen concentration, and heating rate, as shown by Fierro et al. [27], Malet and Caballero [44] and Monti and Baiker [45].
Interpretation of TPR profiles can be further complicated by $\mathrm{H}_{2}$ adsorption/desorption phenomena (e.g. $\mathrm{H}_{2}$ adsorption on or desorption from reduced metal or support sites), as pointed out recently by Fierro et al. [27] and Zotin et al. [43]. It is also important to note that adsorption/desorption of the reduction product (water) on the support can influence the TPR profile as discussed by Bethke et al. [46]. The typical TPR characteristics, namely, the temperature corresponding to the maximum reduction rate, and the shape of the profile itself, are affected by experimental operating variables $[44,45]$. Thus, it is important to carefully account for such effects in planning the TPR experiments.

The effect of operating conditions on the TPR profile of $15 \% \mathrm{CuZr}(\mathrm{Y}) \mathrm{O}_{2}$ catalyst was studied by changing the total flow rate and the heating rate. There was an effect of operating conditions on the maximum temperature peak and peak shape. In all experiments the initial amount of reducible species was approximately the same. When the flow rate was decreased from 500 to $300 \mathrm{~cm}^{3} / \mathrm{min}$ for the same heating rate, the peak maximum shifted slightly to higher temperatures (by $7^{\circ} \mathrm{C}$ ). Also as the heating rate increases for the same flow rate, the peak becomes broader and as a consequence, the peak maximum shifts to higher temperature (by $10^{\circ} \mathrm{C}$ ). The same effect of the operating conditions on the peak position was observed for the $5 \% \mathrm{CuZr}(\mathrm{Y}) \mathrm{O}_{2}$ and $15 \% \mathrm{CuCe}(\mathrm{La}) \mathrm{O}_{2}$ catalysts.

TPR profiles of $\mathrm{CuZr}(\mathrm{Y}) \mathrm{O}_{2}$ catalysts with different copper loading are shown in Fig. 5. The reduction

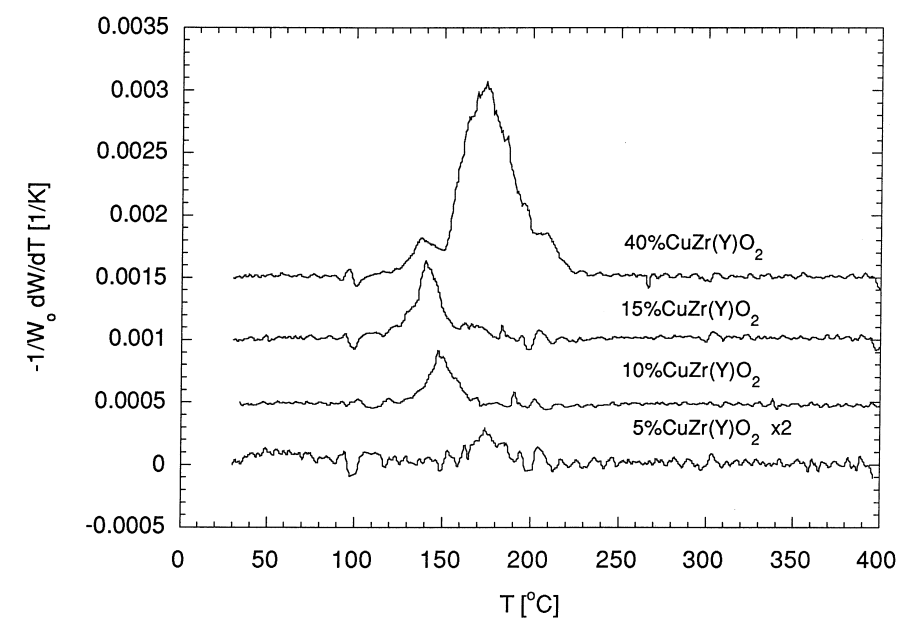

Fig. 5. $\mathrm{H}_{2}$-TPR of $\mathrm{CuZr}(\mathrm{Y}) \mathrm{O}_{2}$ catalysts: TGA, $500 \mathrm{~cm}^{3} \mathrm{~min}^{-1}$ (STP), $5 \% \mathrm{H}_{2} / \mathrm{He}, 5^{\circ} \mathrm{C} / \mathrm{min}$. 
profile changes significantly as the copper loading increases. The $10 \% \mathrm{CuZr}(\mathrm{Y}) \mathrm{O}_{2}$ gives only one reduction peak with a maximum at $140^{\circ} \mathrm{C}$. As the $\mathrm{Cu}$ loading increases from $10 \%$ to $15 \%$, a second reduction peak appears with a maximum at about $165^{\circ} \mathrm{C}$. At a very high $\mathrm{Cu}$ content (40 at\%), reduction starts at about $120^{\circ} \mathrm{C}$, a large reduction peak is observed at $175^{\circ} \mathrm{C}$ and a small reduction peak at about $140^{\circ} \mathrm{C}$. Similar reduction behavior was reported by Amenomiya et al. [33] and Kung et al. [34] for $\mathrm{Cu}-\mathrm{ZrO}_{2}$. Large differences in the reduction profiles between catalysts with different $\mathrm{Cu}$ contents suggests that the state of $\mathrm{Cu}$ significantly changes as the $\mathrm{Cu}$ content changes. For a low $\mathrm{Cu}$ content (5 at\%), reduction starts at about $150^{\circ} \mathrm{C}$ and the peak maximum is observed at $175^{\circ} \mathrm{C}$. The reduction extent calculated from the weight change is slightly lower than that necessary for the complete reduction of $\mathrm{CuO}$ to metallic copper (based on the nominal catalyst composition). Previous studies of $\mathrm{Cu}-\mathrm{ZrO}_{2}$ systems $[33,34]$ have reported that complete $\mathrm{CuO}$ reduction occurs.

A similar effect of $\mathrm{Cu}$ loading is observed for the $\mathrm{CuCe}(\mathrm{La}) \mathrm{O}_{2}$ catalysts as shown in Fig. 6. The reduction extent corresponds to complete reduction of $\mathrm{CuO}$ to $\mathrm{Cu}$ as shown in Table 2. At least three different $\mathrm{Cu}$ species are observed. At low $\mathrm{Cu}$ content (10-15 at\%) the maximum reduction rate was observed at around $160^{\circ} \mathrm{C}$. For the catalyst with high $\mathrm{Cu}$ content (40 at $\%$ $\mathrm{Cu}$ ), reduction starts around $160^{\circ} \mathrm{C}$, and the temperature for maximum reduction rate is observed at $200^{\circ} \mathrm{C}$.

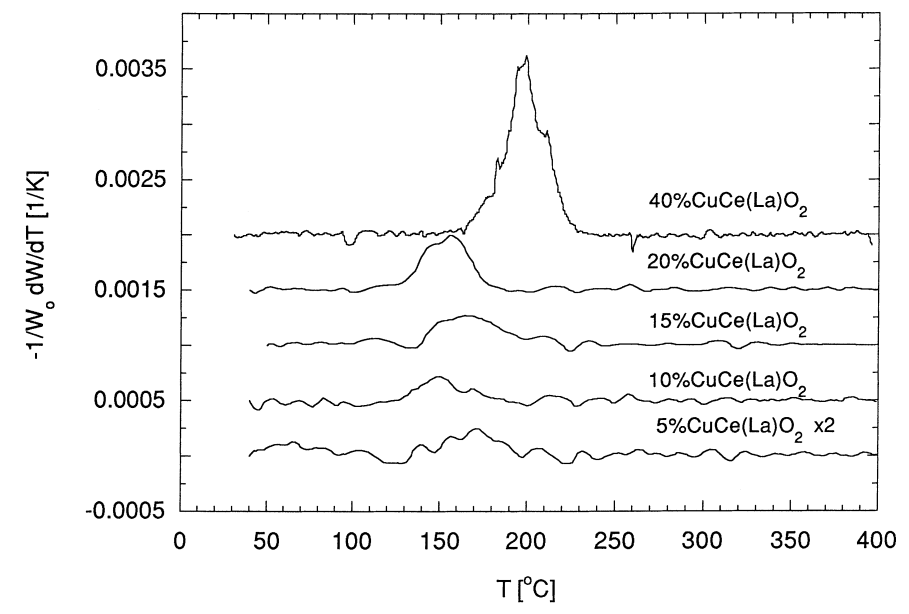

Fig. 6. $\mathrm{H}_{2}$-TPR of $\mathrm{CuCe}(\mathrm{La}) \mathrm{O}_{2}$ catalysts: TGA, $500 \mathrm{~cm}^{3} \min ^{-1}$ (STP), $5 \% \mathrm{H}_{2} / \mathrm{He}, 5^{\circ} \mathrm{C} / \mathrm{min}$.

Table 2

Reduction extent of different $\mathrm{CuCe}(\mathrm{La})-\mathrm{O}$ catalysts in $\mathrm{H}_{2}$-TPR

\begin{tabular}{|c|c|c|c|c|}
\hline Catalyst & $\mathrm{Cu}($ at $\%)$ & $\mathrm{CuO}(\mathrm{wt} \%)$ & $\begin{array}{l}\% \text { Weight change } \\
\text { for } \mathrm{CuO} \text { reduction }\end{array}$ & $\begin{array}{l}\mathrm{CuO} \text { peak } \\
\text { area }(\mathrm{wt} \%)^{\mathrm{b}}\end{array}$ \\
\hline $5 \% \mathrm{CuCe}(\mathrm{La})$ & 4.94 & 2.35 & 0.47 & 0.83 \\
\hline $10 \% \mathrm{CuCe}(\mathrm{La})$ & 9.00 & 4.37 & 0.88 & 1.06 \\
\hline $15 \% \mathrm{CuCe}(\mathrm{La})$ & 12.87 & 6.39 & 1.29 & 1.31 \\
\hline $20 \% \mathrm{CuCe}(\mathrm{La})$ & 17.60 & 8.98 & 1.81 & 1.88 \\
\hline $\mathrm{HNO}_{3}$-washed & & & & 0.81 \\
\hline $25 \%$ nano- $\mathrm{CuO}-\mathrm{CeO}_{2}$ & 25.00 & 13.35 & 2.69 & 3.1 \\
\hline $40 \% \mathrm{CuCe}(\mathrm{La})$ & 40.00 & 23.55 & 4.74 & 4.56 \\
\hline $\mathrm{HNO}_{3}$-washed & & & & 0.6 \\
\hline
\end{tabular}

${ }^{\mathrm{a}}$ Calculated for complete reduction of $\mathrm{CuO}$ to $\mathrm{Cu}$.

${ }^{\mathrm{b}}$ Determined from weight change between $100^{\circ} \mathrm{C}$ and $250^{\circ} \mathrm{C}$. 
Finally, at very low levels of copper, similar to the case of $5 \% \mathrm{CuZr}(\mathrm{Y}) \mathrm{O}_{2}$, the $5 \% \mathrm{CuCe}(\mathrm{La}) \mathrm{O}_{2}$ material shows a broad reduction peak with a maximum at about $175^{\circ} \mathrm{C}$.

The observed reduction behavior may be attributed to structural differences described above for different $\mathrm{Cu}$ contents. With $\mathrm{Cu}$ content in the range 5-20 at\%, copper is mainly at the surface in the form of small copper clusters (Fig. 2(b) in [19]), which are reduced more easily than bulk $\mathrm{CuO}$. The reduction peak at $150-160^{\circ} \mathrm{C}$ is $40-50^{\circ} \mathrm{C}$ lower than the peak temperature for bulk $\mathrm{CuO}$ reduction. At low $\mathrm{Cu}$ loading ( $\sim 5 \%), \mathrm{Cu}$ is present as highly dispersed clusters or as isolated $\mathrm{Cu}$ ions. Copper ions strongly interact with support, and reduction requires higher temperature of $175^{\circ} \mathrm{C}$ (Fig. 6). It is also possible that reduction at low $\mathrm{Cu}$ contents requires diffusion of $\mathrm{H}_{2}$ into the lattice, or diffusion of lattice oxygen to the surface. Finally, at high $\mathrm{Cu}$ loading (40\%), copper is mainly present as larger particles (Fig. 2(c)), and the reduction temperature approaches that for bulk $\mathrm{CuO}\left(230^{\circ} \mathrm{C}\right.$ as reported by Fierro et al. [27]).

Fig. 7 compares the TPR profiles of several CuCe(La) $\mathrm{O}_{2}$ catalysts with a catalyst prepared by mixing nano- $\mathrm{CuO}$ powder with $\mathrm{CeO}_{2}$. The reduction profile of nano- $\mathrm{CuO}$ catalyst has two peaks: the first one at $150^{\circ} \mathrm{C}$ was assigned to small $\mathrm{CuO}$ crystallites in contact with $\mathrm{CeO}_{2}$ [22]; the second peak at $180^{\circ} \mathrm{C}$ was assigned to larger $\mathrm{CuO}$ particles not in intimate contact with $\mathrm{CeO}_{2}$. Wrobel et al. [35] also observed lower reduction peak temperatures for the $\mathrm{Cu}-\mathrm{CeO}_{2}$ system $\left(\sim 130^{\circ} \mathrm{C}\right)$ in materials prepared by coprecipitation of corresponding nitrates by sodium hydroxide. Comparison with TPR profiles of coprecipitated catalysts suggests that the low TPR peaks of coprecipitated catalysts should be assigned to dispersed small $\mathrm{CuO}$ clusters in contact with $\mathrm{CeO}_{2}$, while the high temperature peak should be assigned to larger $\mathrm{CuO}$ particles not in contact with $\mathrm{CeO}_{2}$. Previous work of Liu [17] using STEM/EDS, XRD and XPS found that copper exists in $\mathrm{CuCe}(\mathrm{La}) \mathrm{O}_{2}$ catalysts in three states: isolated $\mathrm{Cu}^{2+}$ ions, small clusters of $\mathrm{CuO}_{x}$ and as $\mathrm{CuO}$ particles. The reducibility of these species in $\mathrm{H}_{2}$ is different. While the clusters are reduced at $\sim 130$ $160^{\circ} \mathrm{C}$, the larger $\mathrm{CuO}$ particles have more of the bulk oxide character and are reduced at $\sim 200^{\circ} \mathrm{C}$. We believe that the intermediate temperature of $180^{\circ} \mathrm{C}$ is characteristic of the reduction of isolated ions strongly associated with the support.

Reduction of $\mathrm{Cu}-\mathrm{ZrO}_{2}$ catalysts was studied by Amenomiya et al. [33]. At low $\mathrm{Cu}$ content (14.7 at \%), the maximum reduction rate was observed at $200^{\circ} \mathrm{C}$, whereas at high $\mathrm{Cu}$ content $(50$ at $\%$ ), two reduction peaks were observed, a low-temperature one at $200^{\circ} \mathrm{C}$ and one at a high temperature, $300^{\circ} \mathrm{C}$. Kung et al. [34] reported much lower temperatures for the reduction of $\mathrm{Cu}-\mathrm{ZrO}_{2}$ catalysts. For 11 at $\% \mathrm{Cu}$ they observed a maximum reduction rate at $134^{\circ} \mathrm{C}$, while

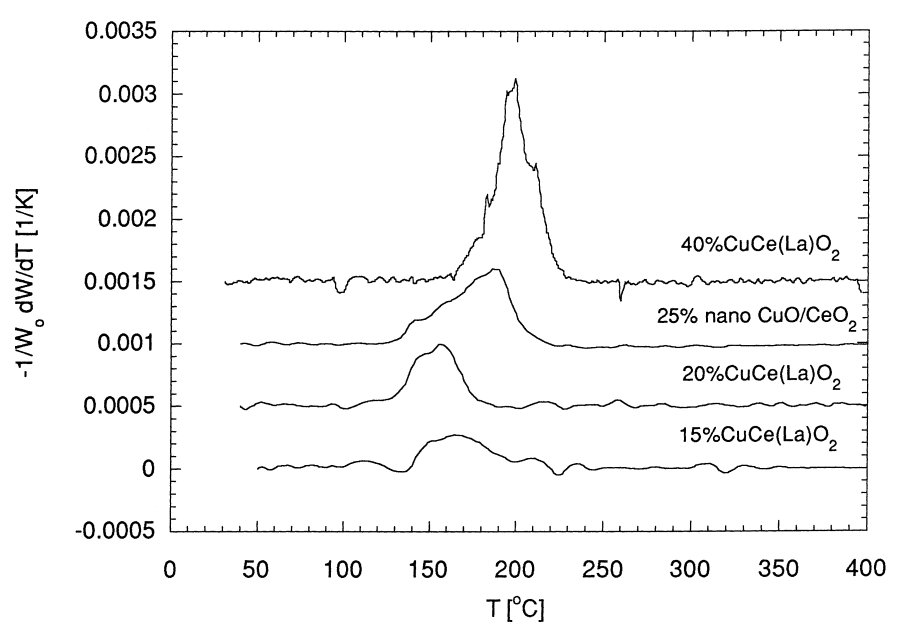

Fig. 7. Comparison of $\mathrm{H}_{2}-\mathrm{TPR}$ of coprecipitated $\mathrm{CuCe}(\mathrm{La}) \mathrm{O}_{2}$ catalysts with the $\mathrm{H}_{2}-\mathrm{TPR}$ of physical mixture of nano-CuO and Ce( $\left.\mathrm{La}\right) \mathrm{O}_{2}$ : TGA, $500 \mathrm{~cm}^{3} \mathrm{~min}^{-1}$ (STP), $5 \% \mathrm{H}_{2} / \mathrm{He}, 5^{\circ} \mathrm{C} / \mathrm{min}$. 
for 43.3 at $\% \mathrm{Cu}$ a low-temperature peak was observed at $150^{\circ} \mathrm{C}$ and a high-temperature reduction peak was observed at $180^{\circ} \mathrm{C}$. The reduction profiles of $\mathrm{Cu}$ in $\mathrm{Y}$ doped $\mathrm{ZrO}_{2}$ repeated here are very similar to those observed by the latter group.

Comparison of the TPR profiles of catalysts as prepared and after treatment in $\mathrm{HNO}_{3}$ (dissolving $\mathrm{CuO}$, but not $\mathrm{CeO}_{2}$ or $\mathrm{ZrO}_{2}$ ), and calcination of the resulting material at $650^{\circ} \mathrm{C}$ is shown in Fig. 8. Inspection of the TPR profiles of $40 \% \quad \mathrm{CuCe}(\mathrm{La}) \mathrm{O}_{2}$ (Fig. 8(a)) and 20\% $\mathrm{CuCe}(\mathrm{La}) \mathrm{O}_{2}$ (Fig. 8(b)) shows that after the larger $\mathrm{CuO}$ particles had been removed by $\mathrm{HNO}_{3}$, the temperature for maximum reduction rate for both catalysts was $150-160^{\circ} \mathrm{C}$. Similar behavior was observed for the $40 \% \mathrm{CuZr}(\mathrm{Y}) \mathrm{O}_{2}$ as shown in Fig. 8(c). All acid-washed catalysts had TPR profiles similar to low $\mathrm{Cu}$-containing catalysts (Figs. 5 and 6). Liu and Flytzani-Stephanopoulos [22] have found only clusters of copper remaining in the acid-washed materials, which accounts for the present TPR data.

The above discussion focuses on the reducibility of $\mathrm{CuO}$ in $\mathrm{CeO}_{2}$ and $\mathrm{ZrO}_{2}$. However, it is also interesting to examine the reducibility of the oxide support itself. While a more extensive study of cerium oxide reducibility resulting from interaction with transition metals is presented elsewhere [46], we have a clear indication of ceria reduction by $\mathrm{H}_{2}$ even at this low temperature $\left(<200^{\circ} \mathrm{C}\right)$. In Table 2 , the extent of reduction (expressed as wt\% change) exceeds that corresponding to the complete reduction of copper oxide to the metal, almost 1.7 times for the $5 \% \mathrm{CuCe}(\mathrm{La}) \mathrm{O}_{2}$ sample. This excess oxygen reduction was especially pronounced for the low-content copper samples, where the copper clusters are strongly associated with ceria (see also [22]). Similar behavior was observed by Delk and Vavere [30] for copper supported on titania. No such interaction is present in the $\mathrm{CuZr}(\mathrm{Y}) \mathrm{O}_{2}$ samples.

\subsection{2. $\mathrm{CH}_{4}-\mathrm{TPR}$}

Fig. 9 shows the $\mathrm{CH}_{4}$-TPR profiles of copper-modified catalysts obtained by monitoring the product $\mathrm{CO}_{2}$ by mass spectrometry. Reaction of methane with these oxidized catalysts gives $\mathrm{CO}_{2}$ and $\mathrm{H}_{2} \mathrm{O}$ as reduction products. Only trace amounts of $\mathrm{CO}$ were observed. Fig. 9 shows the $\mathrm{CH}_{4}$-TPR of $\mathrm{Cu}$-modified catalysts shown as $\mathrm{CO}_{2}$ evolution vs. temperature. As it can be seen in Fig. 9(a), different $\mathrm{Cu}$ species on $\mathrm{Zr}(\mathrm{Y}) \mathrm{O}_{2}$ react with methane in a different way. Generally, the same reduction behavior was observed as in the reduction by hydrogen. At low $\mathrm{Cu}$ loading ( 5 at\%), only a single reduction peak was observed. These highly dispersed $\mathrm{Cu}$ species begin to react with methane at about $350^{\circ} \mathrm{C}$, and the peak maximum is observed at $\sim 400^{\circ} \mathrm{C}$. On the other hand, at a $\mathrm{Cu}$ content $>10$ at $\%$, reduction starts at $300^{\circ} \mathrm{C}$, and a doublet is observed. A doublet is also present in the TPR profile of $40 \% \mathrm{CuZr}(\mathrm{Y}) \mathrm{O}_{2}$, suggesting that its origin is bulk $\mathrm{CuO}$. The most reducible species appear to be $\mathrm{Cu}$ clusters (identified by STEM/EDX in the $15 \% \mathrm{CuZr}(\mathrm{Y}) \mathrm{O}_{2}$ catalysts, Fig. 2), which are in close contact with the support.

A similar reduction pattern is observed for $\mathrm{CuCe}$ (La) $\mathrm{O}_{2}$ catalysts (Fig. 9(b)). The $5 \% \mathrm{CuCe}(\mathrm{La}) \mathrm{O}_{2}$ catalyst shows one peak in the $\mathrm{CH}_{4}$-TPR, with maximum reduction at about $450^{\circ} \mathrm{C}$. As the $\mathrm{Cu}$ content increases to 15 at $\%$, a doublet appears in the reduction profile and reduction starts at about $300^{\circ} \mathrm{C}$. As in $\mathrm{H}_{2-}$ TPR, copper clusters in close contact with $\mathrm{CeO}_{2}$ support are more easily reduced than highly dispersed copper. The reason for this must be the strong interaction of dispersed copper species with the $\mathrm{CeO}_{2}$ matrix. Comparison of the TPR profile of $40 \% \mathrm{CuCe}$ ( $\mathrm{La}) \mathrm{O}_{2}$ catalyst as prepared with the TPR of the catalyst treated with $\mathrm{HNO}_{3}$ (where bulk $\mathrm{CuO}$ particles were removed) shows that copper clusters are more reducible than bulk $\mathrm{CuO}$, also in agreement with what was observed in $\mathrm{H}_{2}$-TPR (Fig. 8(a) and (b)). Reduction of bulk $\mathrm{CuO}$ (prepared by carbonate decomposition) is shown for comparison, indicating that the doublet in the reduction profile comes from bulk $\mathrm{CuO}$ reduction. Fig. 9(b) shows that the peak maximum shifts to higher temperatures as the copper content increases from $15 \%$ to $40 \%$. To check for possible effect of the reduction conditions as the amount of reducible species increases, we performed $\mathrm{CH}_{4}$-TPR in the TGA setup under significantly different conditions $(\sim 40$ times less catalyst and $\sim 10$ times higher flow rate of the reducing gas). As shown in Fig. 9(c) for the 5\%, $15 \%$, and $40 \% \mathrm{CuCe}(\mathrm{La}) \mathrm{O}_{2}$ materials, reduction starts at about $300^{\circ} \mathrm{C}$ for high $\mathrm{Cu}$ loading $(15 \%$ and $40 \%$ $\mathrm{Cu}$ ), and at about $350^{\circ} \mathrm{C}$ for the low $\mathrm{Cu}$ loading $(5$ at $\%)$. A rather broad reduction peak $\left(350-500^{\circ} \mathrm{C}\right)$ is observed at low $\mathrm{Cu}$ loading. The unusual peak shape at high $\mathrm{Cu}$ contents comes from the complex desorption $\left(\mathrm{H}_{2} \mathrm{O}, \mathrm{CO}_{2}\right)$ pattern during the reduction. 

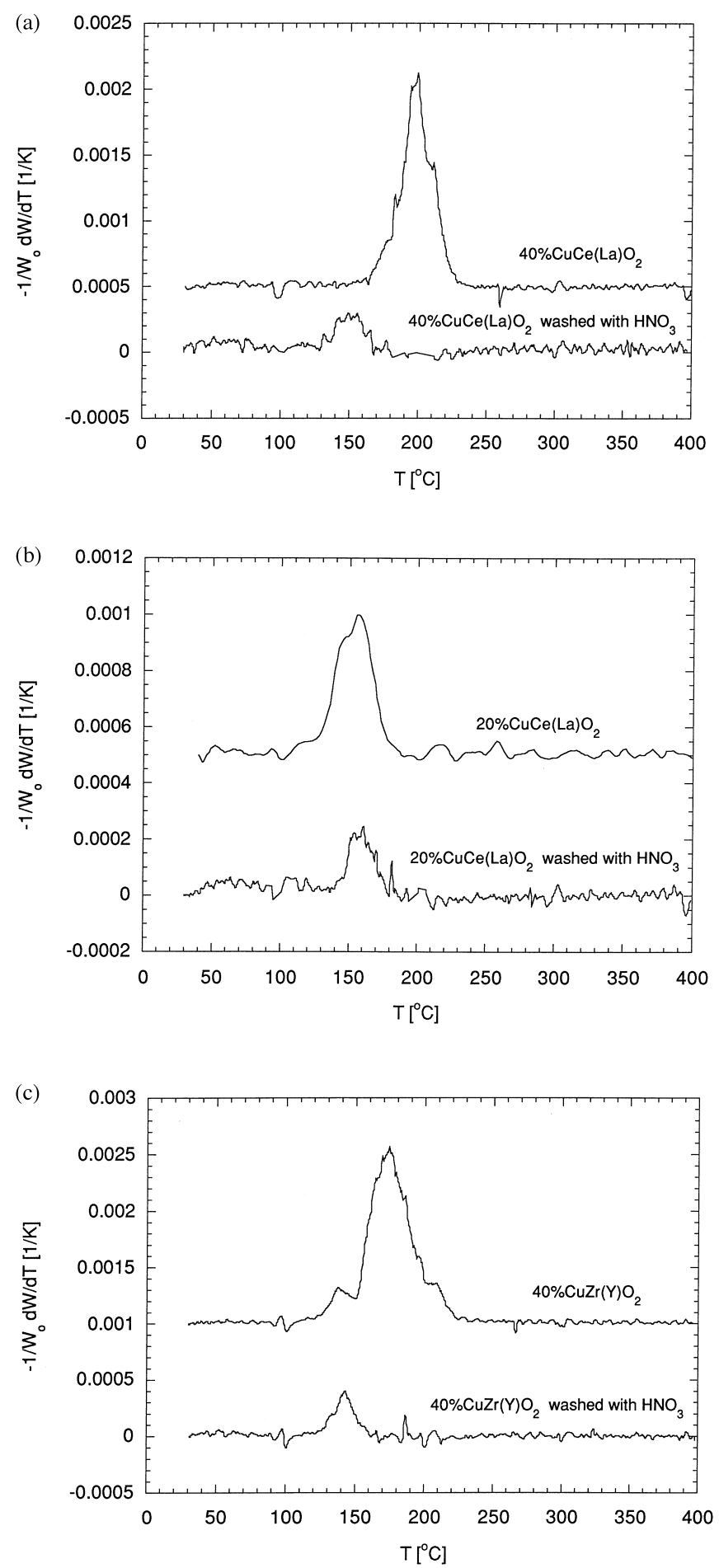

Fig. 8. $\mathrm{H}_{2}$-TPR of high $\mathrm{CuO}$ loading catalysts before and after nitric acid treatment (TGA, $500 \mathrm{~cm}^{3} \mathrm{~min}^{-1}$ (STP), $\left.5 \% \mathrm{H} / \mathrm{He}, 5^{\circ} \mathrm{C} / \mathrm{min}\right):($ a) $40 \% \mathrm{CuCe}(\mathrm{La}) \mathrm{O}_{2}$, (b) $20 \% \mathrm{CuCe}(\mathrm{La}) \mathrm{O}_{2}$, (c) $40 \% \mathrm{CuZr}(\mathrm{Y}) \mathrm{O}_{2}$. 
(a)

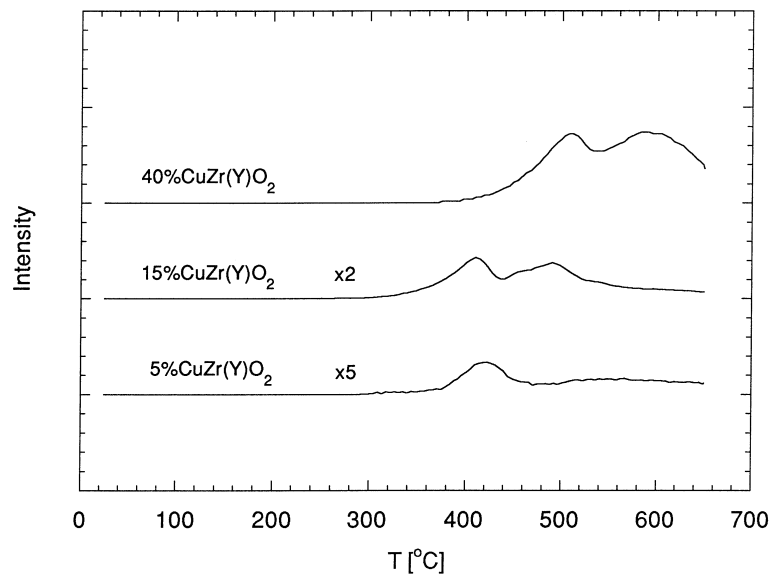

(b)
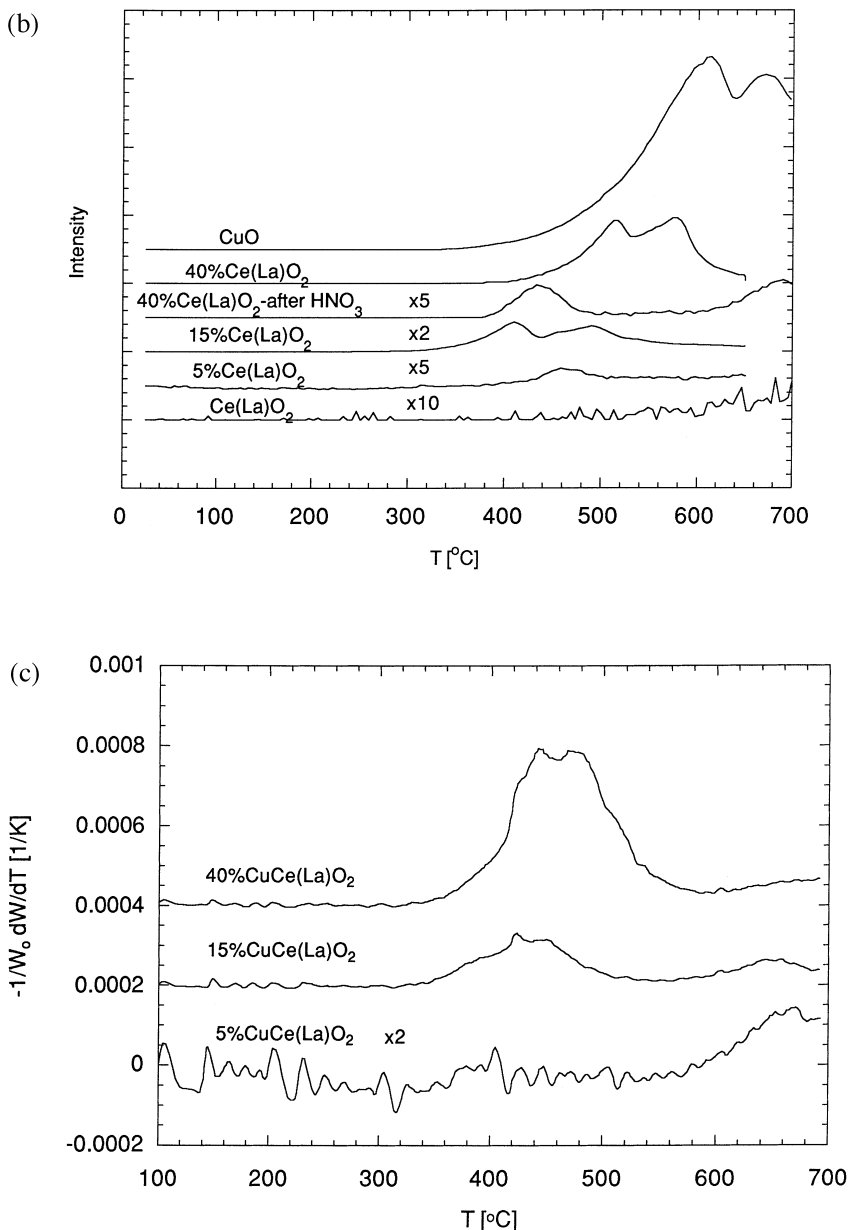

Fig. 9. (a) $\mathrm{CH}_{4}$-TPR of $\mathrm{CuZr}(\mathrm{Y}) \mathrm{O}_{2}$ catalysts with different copper loading: Reactor-MS, $200 \mathrm{mg}$ catalyst, $50 \mathrm{~cm}^{3} \mathrm{~min}^{-1}(\mathrm{STP}), 5 \% \mathrm{CH}_{4} / \mathrm{He}$, $10^{\circ} \mathrm{C} / \mathrm{min}$. (b) $\mathrm{CH}_{4}-\mathrm{TPR}$ of $\mathrm{CuCe}(\mathrm{La}) \mathrm{O}_{2}$ catalysts with different copper loading: Reactor-MS, $200 \mathrm{mg}$ catalyst, $50 \mathrm{~cm}^{3} \mathrm{~min}^{-1}(\mathrm{STP}), 5 \% \mathrm{CH}_{4} / \mathrm{He}$, $10^{\circ} \mathrm{C} / \mathrm{min}$. (c) $\mathrm{CH}_{4}-\mathrm{TPR}$ of $\mathrm{CuCe}(\mathrm{La}) \mathrm{O}_{2}$ catalysts with different copper loading: $\mathrm{TGA}, 5 \mathrm{mg}$ catalyst, $500 \mathrm{~cm}^{3} \mathrm{~min}^{-1}(\mathrm{STP}), 5 \% \mathrm{CH}_{4} / \mathrm{He}, 10^{\circ} \mathrm{C} / \mathrm{min}$. 
Table 3

Reduction extent of different $\mathrm{CuCe}(\mathrm{La})-\mathrm{O}$ catalysts in $\mathrm{CH}_{4}$-TPR

\begin{tabular}{|c|c|c|c|c|}
\hline Catalyst & $\mathrm{Cu}(\mathrm{at} \%)$ & $\mathrm{CuO}(\mathrm{wt} \%)$ & $\begin{array}{l}\% \text { Weight change for } \\
\mathrm{CuO} \text { reduction }{ }^{\mathrm{a}}\end{array}$ & $\begin{array}{l}\mathrm{CuO} \text { peak } \\
\text { area }(\mathrm{wt} \%)\end{array}$ \\
\hline $5 \% \mathrm{CuCe}(\mathrm{La})$ & 4.94 & 2.35 & 0.47 & $0.86^{\mathrm{b}}$ \\
\hline $15 \% \mathrm{CuCe}(\mathrm{La}$ & 12.87 & 6.39 & 1.29 & $1.36^{\mathrm{b}}$ \\
\hline $40 \% \mathrm{CuCe}(\mathrm{La})$ & 40.00 & 23.55 & 4.74 & $4.77^{\mathrm{c}}$ \\
\hline
\end{tabular}

${ }^{\mathrm{a}}$ Calculated for complete reduction of $\mathrm{CuO}$ to $\mathrm{Cu}$.

${ }^{\mathrm{b}}$ Determined from weight change between $300^{\circ} \mathrm{C}$ and $520^{\circ} \mathrm{C}$.

${ }^{\mathrm{c}}$ Determined from weight change between $300^{\circ} \mathrm{C}$ and $580^{\circ} \mathrm{C}$.

The reduction extent in $\mathrm{CH}_{4}$-TPR of $\mathrm{CuCe}(\mathrm{La}) \mathrm{O}_{2}$ catalysts is shown in Table 3. As in the $\mathrm{H}_{2}$-TPR (Table 2), the observed weight change at high $\mathrm{Cu}$ loading is close to the amount of oxygen removed if all $\mathrm{CuO}$ is reduced to metallic $\mathrm{Cu}$. Only at low $\mathrm{Cu}$ content $\left(5\right.$ at $\%$ ), the amount reduced in both $\mathrm{H}_{2}$ - and $\mathrm{CH}_{4}$-TPR is much higher than what would account for just the copper (as $\mathrm{CuO}$ ). The additional oxygen removed is attributed to the reduction of ceria induced by the presence of $\mathrm{Cu}$. As mentioned above, enhancement of ceria reducibility by addition of copper was reported [22] in reduction by $\mathrm{H}_{2}$. Here we see that $\mathrm{CH}_{4}$ can also be used to observe this enhancement. In addition, $\mathrm{CH}_{4}$-TPR is useful as it identifies the temperature range where the mixed oxide system will show activity for the methane oxidation, assuming that the latter operates according to the redox mechanism.

\subsection{Kinetic measurements}

The activity of the various catalysts for methane oxidation was also compared under kinetic control. Complete kinetic studies were performed over the $\mathrm{Ce}(\mathrm{La}) \mathrm{O}_{2}$ [47] and $15 \% \mathrm{CuCe}(\mathrm{La}) \mathrm{O}_{2}$ catalysts [20]. The reaction order with respect to methane partial pressure was found to be close to 1 on both catalysts, while the reaction order with respect to oxygen partial pressure is close to zero $\left(0.23\right.$ for $\mathrm{Ce}(\mathrm{La}) \mathrm{O}_{2}$, and 0.18 for the $\mathrm{Cu}$-modified catalyst). Here we are reporting on rate measurements and apparent activation energies with the $\mathrm{Ce}(\mathrm{La}) \mathrm{O}_{2}$ and $\mathrm{Zr}(\mathrm{Y}) \mathrm{O}_{2}$-based catalysts. Fig. 10(a) and (b) show Arrhenius-type plots for the rate of methane oxidation over various $\mathrm{CuCe}(\mathrm{La}) \mathrm{O}_{2}$ and $\mathrm{CuZr}(\mathrm{Y}) \mathrm{O}_{2}$ catalysts. For all $\mathrm{CeO}_{2}$-based catalysts, the rates of methane oxidation are similar at all $\mathrm{Cu}$ loading with activation energies ranging from 85.5 to $119 \mathrm{~kJ} / \mathrm{mol}$ (Fig. 10(a)). Increase in $\mathrm{Cu}$ content from 5 to 15 at\% slightly increases the activity for methane oxidation. Further addition of copper does not significantly change the activity as is evident from the activity of the $40 \% \mathrm{CuCe}(\mathrm{La}) \mathrm{O}_{2}$ sample as prepared and after bulk $\mathrm{CuO}$ was removed by nitric acid. Fig. 10(a) also shows the Arrhenius-type plot for $\mathrm{CH}_{4}$ oxidation over the La-doped cerium oxide in the absence of copper. The activation energy is similar while the reaction rate is lower. This indicates that the enhancement of methane oxidation by addition of copper in $\mathrm{Ce}(\mathrm{La}) \mathrm{O}_{2}$ is derived from an increase in the surface oxygen species.

The activity of $\mathrm{CuZr}(\mathrm{Y}) \mathrm{O}_{2}$ catalysts for methane oxidation is shown in Fig. 10(b). The effect of $\mathrm{Cu}$ is more pronounced here than in the $\mathrm{CuCe}(\mathrm{La}) \mathrm{O}_{2}$ samples. The methane oxidation rate increases as the copper loading increases from $5 \%$ to $15 \%$, especially at low temperatures, indicating that copper clusters are more active for methane oxidation than highly dispersed copper. Further addition of copper (40\%) forms bulk $\mathrm{CuO}$ particles, which do not contribute further to the catalytic activity.

Differences between the two supports are evident only for low $\mathrm{Cu}$ loading (5 at\%), where $\mathrm{CeO}_{2}$-based catalysts show higher activity at low temperatures than the $\mathrm{ZrO}_{2}$-based materials. This is attributed to the participation of ceria in the reaction. At higher $\mathrm{Cu}$ loading, the surface of ceria is progressively covered with more copper so that the ceria does not contribute significantly to the activity. Overall, ceria appears to be a better support for copper as the activity of the 5\% $\mathrm{CuZr}(\mathrm{Y}) \mathrm{O}_{2}$ catalyst decreased significantly after a high-temperature treatment at $750^{\circ} \mathrm{C}$ (Fig. 10(b)), while that of the $5 \% \mathrm{CuCe}(\mathrm{La}) \mathrm{O}_{2}$ catalyst remained unaffected (shown in Fig. 10(a)). Thus, the interaction 

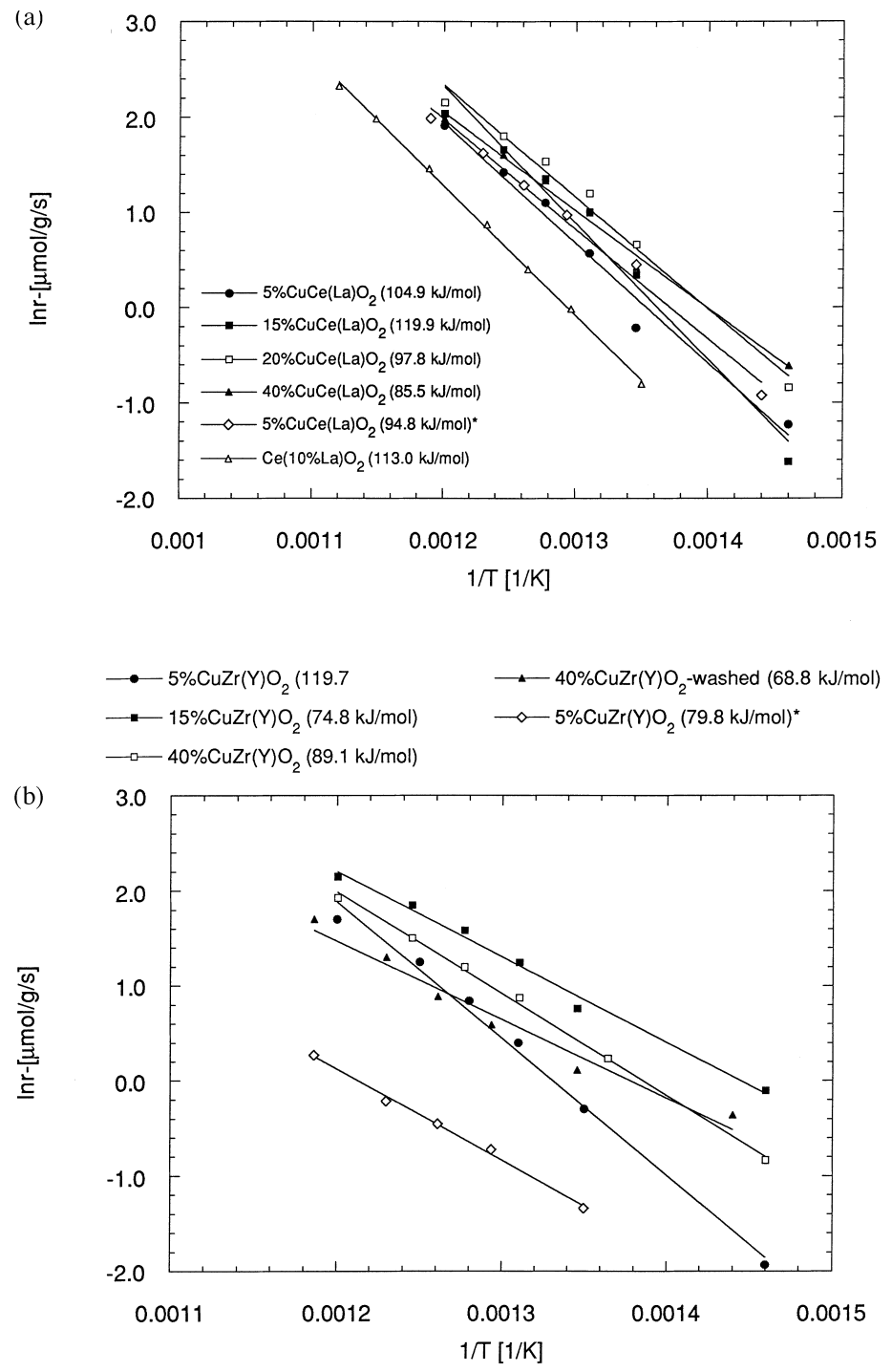

Fig. 10. (a) Arrhenius-type plot of the rate of methane oxidation on Cu-modified $\mathrm{CeO}_{2}$ based catalysts $\left(650^{\circ} \mathrm{C}\right.$-calcined): $0.024 \mathrm{~g} \mathrm{~s} / \mathrm{cm}^{3}, 1 \%$ $\mathrm{CH}_{4}, 5 \% \mathrm{O}_{2}$, balance $\mathrm{He} *$ (further heated in air at $750^{\circ} \mathrm{C}$ for $5 \mathrm{~h}$ ). (b) Arrhenius-type plot of the rate of methane oxidation on Cu-modified $\mathrm{ZrO}_{2}$ based catalysts $\left(650^{\circ} \mathrm{C}\right.$-calcined): $0.024 \mathrm{~g} \mathrm{~s} / \mathrm{cm}^{3}, 1 \% \mathrm{CH}_{4}, 5 \% \mathrm{O}_{2}$, balance $\mathrm{He} *$ (further heated in air at $750^{\circ} \mathrm{C}$ for $5 \mathrm{~h}$ ).

of copper species with ceria reported earlier [17] prevents sintering and loss of surface oxygen, thus retaining a high methane oxidation activity.

In general, highly dispersed copper species are less active for methane oxidation than $\mathrm{Cu}$ clusters formed on each support at higher loading (5-20 at\%). The observed behavior may be attributed to the higher reducibility of these clusters. Bulk $\mathrm{CuO}$ particles, which are formed at high $\mathrm{Cu}$ loading (40 at\%) are reduced at higher temperature and do not contribute to the overall catalytic activity (Fig. 10).

\section{Summary}

In this paper, the reducibility of $\mathrm{Cu}$-containing cerium and zirconium oxide systems was studied both by $\mathrm{H}_{2}$-TPR and $\mathrm{CH}_{4}$-TPR and was correlated with the 
various copper species present. Studies were complemented by characterization of the mixed oxides by STEM/EDX, XRD and XPS. Finally, the catalytic activity of these systems for the complete oxidation of methane at low temperatures was studied and correlated to the presence of the reducible oxide species.

Hydrogen reduction of $\mathrm{CuO}$ in the $\mathrm{Ce}(\mathrm{La}) \mathrm{O}_{2}$ and $\mathrm{Zr}(\mathrm{Y}) \mathrm{O}_{2}$ oxide systems was studied here to identify different copper species based on their reduction behavior. At low $\mathrm{Cu}$ loading ( $\sim 5 \%)$, on both oxides studied, reduction by $\mathrm{H}_{2}$ gives a broad peak with a maximum around $175^{\circ} \mathrm{C}$. Copper is present as highly dispersed clusters or as isolated $\mathrm{Cu}$ ions. These interact strongly with the support, and the reduction requires a temperature of $175^{\circ} \mathrm{C}$. At higher $\mathrm{Cu}$ content (5-20 at\%), copper is mainly at the surface present as small clusters, which are reduced more easily so that the reduction peak is observed at lower temperature $\left(145^{\circ} \mathrm{C}\right.$ for $\mathrm{Zr}(\mathrm{Y}) \mathrm{O}_{2}$-based catalysts and $160^{\circ} \mathrm{C}$ for $\mathrm{Ce}(\mathrm{La}) \mathrm{O}_{2}$-based catalysts $)$. On the other hand, at high $\mathrm{Cu}$ loading $(\sim 40 \%)$, copper is present mainly as larger $\mathrm{CuO}$ particles, which do not interact strongly with the support, as indicated by a reduction temperature approaching that for bulk $\mathrm{CuO}\left(180^{\circ} \mathrm{C}\right.$ on $\mathrm{Zr}(\mathrm{Y}) \mathrm{O}_{2^{-}}$ based catalysts and $200^{\circ} \mathrm{C}$ for the $\mathrm{Ce}(\mathrm{La}) \mathrm{O}_{2}$-based catalysts).

There is a clear influence of the oxide host on the reducibility of copper. In turn, copper increases the reducibility of ceria. It seems that copper is more stabilized when dispersed in $\mathrm{Ce}(\mathrm{La}) \mathrm{O}_{2}$ than in the $\mathrm{Zr}(\mathrm{Y}) \mathrm{O}_{2}$ matrix, so that the reduction of copper species occurs at lower temperatures for the $\mathrm{Zr}(\mathrm{Y}) \mathrm{O}_{2}-$ based catalysts.

A similar TPR pattern was observed when methane was used as a reductant. At low copper content (5 at \%), reduction starts at about $350^{\circ} \mathrm{C}$ and a single reduction peak was observed with a maximum at $400^{\circ} \mathrm{C}$. As the copper content increases, a doublet appears in the reduction profile. Highly dispersed copper clusters react with methane at lower temperatures (reduction starts at about $300^{\circ} \mathrm{C}$ ) in agreement with what was observed in $\mathrm{H}_{2}$-TPR. Increase of ceria reducibility by the addition of copper was also observed during $\mathrm{CH}_{4}$-TPR.

The reaction rates for methane oxidation on both $\mathrm{CuCe}(\mathrm{La}) \mathrm{O}_{2}$ and $\mathrm{CuZr}(\mathrm{Y}) \mathrm{O}_{2}$ are in the same range due to the similar activity of copper clusters present on both supports. However, the importance of ceria, which is itself an active catalyst for methane oxidation, is manifested at low $\mathrm{Cu}$ loading and low temperatures, where the $\mathrm{CeO}_{2}$-based material shows better performance than the $\mathrm{ZrO}_{2}$-based one. $\mathrm{CeO}_{2}$ also contributes to the higher thermal stability of the $5 \% \mathrm{Cu}$-containing catalyst, which retains its catalytic activity after a high-temperature treatment. The same high-temperature treatment $\left(750^{\circ} \mathrm{C}, 5 \mathrm{~h}\right.$ in air) significantly decreases the activity of $5 \% \mathrm{CuZr}(\mathrm{Y}) \mathrm{O}_{2}$. The copper clusters formed on both supports appear to be the most active component of the catalyst. Bulk $\mathrm{CuO}$ particles do not contribute to the overall catalytic activity. In general, strongly associated copper (ions) and large copper particles were both found to be less active than copper clusters dispersed on the support.

\section{References}

[1] A. Trovarelli, Catal. Rev.-Sci. Eng. 38(4) (1996) 439.

[2] S. Meriani, Mater. Sci. Eng. A109 (1989) 121.

[3] G. Balducci, P. Fornasiero, R. Di Monte, J. Kaspar, S. Meriani, M. Graziani, Catal. Lett. 33 (1995) 193.

[4] C. De Leitenburg, A. Trovarelli, F. Zamar, S. Maschio, G. Dolcetti, J. Llorca, J. Chem. Soc., Chem. Commun. (1995) 2181.

[5] B. Harrison, A.F. Diwell, C. Hallett, Plat. Met. Rev. 32(2) (1988) 73.

[6] G.S. Zafiris, R.J. Gorte, J. Catal. 139 (1993) 561.

[7] H. Cordatos, R.J. Gorte, J. Catal. 159 (1996) 112.

[8] H. Cordatos, T. Bunluesin, J. Stubenrauch, J.M. Vohs, R.J. Gorte, J. Phys. Chem. 100 (1996) 785.

[9] E.S. Putna, J.M. Vohs, R.J. Gorte, J. Phys. Chem. 100 (1996) 17862.

[10] T. Bunluesin, R.J. Gorte, G.W. Graham, Appl. Catal. B 339 (1997) 1.

[11] A.L. Tarasov, L.K. Przheval'skaya, V.A. Shvets, V.B. Kazanskii, Kinet. Katal. 29(5) (1988) 1181.

[12] C. Li, Y. Chen, W. Li, Q. Xin, in: T. Inui et al. (Eds.), New Aspects of Spillover in Catalysis, Elsevier Science, Amsterdam, 1993, p. 217.

[13] H.C. Yao, Y.F. Yao, J. Catal. 86 (1984) 254.

[14] J.G. Nunan, R.G. Silver, S.A. Bradley, in: R.G. Silver, J.E. Saeyer, J.C. Summers (Eds.), Catalytic Control of Air Pollution, Chap. 17, ACS Symposium Series 495, American Chemical Society, Washington, DC, 1992.

[15] A. Aboukais, A. Bennani, C.F. Aissi, M. Guelton, J.C. Vedrine, Chem. Mater. 4 (1992) 977.

[16] J. Soria, J.C. Conesa, A. Martinez-Arias, J.M. Coronado, Solid State Ionics 63-65 (1993) 755.

[17] W. Liu, Development of Novel Metal Oxide Composite Catalysts for Complete Oxidation Reactions, Sc.D. Thesis, MIT, 1995. 
[18] W. Liu, M. Flytzani-Stephanopoulos, J. Catal. 153 (1995) 304.

[19] W. Liu, M. Flytzani-Stephanopoulos, J. Catal. 153 (1995) 317.

[20] W. Liu, A.F. Sarofim, M. Flytzani-Stephanopoulos, Chem. Eng. Sci. 49(24A) (1994) 4871.

[21] W. Liu, C. Wadia, M. Flytzani-Stephanopoulos, Catal. Today 28 (1996) 391.

[22] W. Liu, M. Flytzani-Stephanopoulos, Chem. Eng. J. 64 (1996) 283.

[23] V.R. Choudhary, B.S. Uphade, S.G. Pataskar, A. Keshavaraja, Angew. Chem. Int. Ed. Engl. 35(20) (1996) 2393.

[24] V. Perrichon, A. Laachir, G. Bergeret, R. Frety, L. Tournayan, O. Touret, J. Chem. Soc., Faraday Trans. 90 (1994) 773.

[25] P. Fornasiero, R. Di Monte, G. Ranga Rao, L. Kaspar, Meriani, A. Trovarelli, M. Graziani, J, Catal. 151 (1995) 168.

[26] J.Y. Yan, G.-D. Lei, W.M.H. Sachtler, H.H. Kung, J. Catal. 160 (1996).

[27] G. Fierro, M. Lo Jacono, M. Inversi, P. Porta, R. Lavecchia, F. Cioci, J. Catal. 148 (1994) 709.

[28] W.-P. Dow, T.-J. Huang, J. Catal. 147 (1994) 322.

[29] W.-P. Dow, Y.-P. Wang, T.-J. Huang, J. Catal. 160 (1996) 155.

[30] F.S. Delk, A. Vavere, J. Catal. 85 (1984) 380.

[31] J. Sárkány, J.L. d'Itri, W.M.H. Sachtler, Catal. Lett. 16 (1992) 241.

[32] T. Beutel, J. Sárkány, G.-D. Lei, J.Y. Yan, M.H. Sachtler, J. Phys. Chem. 100 (1996) 845.

[33] Y. Amenomiya, I. Ali Emesh, K. Oliver, G. Pleizier, in: M. Phillips, M. Ternan (Eds.), Proceedings of the Ninth International Congress on Catalalysis, Chemical Institute of Canada, Ottawa, Canada, 1988, p. 634.
[34] M. Kung, K. Bethke, D. Alt, B. Yang, H. Kung, in: U. Ozkan, S. Agrawal, G. Marcelin (Eds.), ACS Symposium Series, vol. 587, American Chemical Society, Washington, DC, 1995, p. 96.

[35] G. Wrobel, C. Lamonier, A. Bennani, A. D'Huysser, A. Aboukais, J. Chem. Soc., Faraday Trans. 92(11) (1996) 2001.

[36] R.J. Farrauto, J.K. Lampert, M.C. Hobson, M. Waterman, Appl. Catal. B 6 (1995) 263.

[37] K. Otto, Langmuir 5 (1989) 1364.

[38] K. Fujimoto, F.H. Ribiero, E. Iglesia, M. Avalos-Borja, Symposium on Catalytic Combustion, Division on Petroleum Chemistry, 213 National Meeting, American Chemical Society, San Fransisco, CA, 1997.

[39] F. Zamar, A. Trovarelli, C. De Leitenburg, G. Dolcetti, J. Chem. Soc., Chem. Commun. 9 (1995) 965.

[40] J.J.F. Scholten, A.P. Pijpers, M.L. Hustings, Catal. Rev. Sci. Eng. 27(1) (1985) 151.

[41] D. Brigs, M.P. Seah (Eds.), Practical Surface Analysis by Auger and X-ray Photoelectron Spectroscopy, Wiley, New York, 1983.

[42] J.L. Falconer, J.A. Schwarz, Catal. Rev. Sci. Eng. 25(2) (1983) 141.

[43] F.M.Z. Zotin, L. Tournayan, J. Varloud, V. Perrichon, R. Frety, Appl. Catal. A 98 (1993) 99.

[44] P. Malet, A. Caballero, J. Chem. Soc. Faraday Trans. 1 84(7) (1988) 2369.

[45] D.A. Monti, A. Baiker, J. Catal. 83 (1983) 323.

[46] K.A. Bethke, M.C. Kung, B. Yang, M. Shah, D. Alt, C. Li, H.H. Kung, Catal. Today 26 (1995) 169.

[47] Lj. Kundakovic, M. Flytzani-Stephanopoulos, J. Catal. (1998), submitted. 